possible to conceive any state of life more conducive to loss of health and dwarfing of physical development? These poor creatures appear to have no qualifying or redeeming feature in their every-day routine of life. Breathing in their insanitary homes the wreaking fumes of unhealthy surroundings, an atmosphere ritiated to the last degree of respiratory fitness, to which is added unwholesome food and consequent faulty assimilation, the aggregation must inevitably result in depraved constitutional integrity. Nor is there the faintest silver lining to this dark social cloud. These people have not the relieving benefit of sleeping in pure air after a day of hard work of twelve or fourteen hours' duration in the disease-laden atmosphere of insanitary workshops, but are subjected by day and by night to conditions as far removed from the sources of health as the poles are asunder. Their daily occupations and mode of life in the workshop are bad, and their homes also are bad. It is to be hoped the utter desolation of their lives thus brought to light by THE LANCET will stir up the public mind to such a degree as to insist upon an inmediate amelioration of their unlappy condition, and that both homes and workshops will be made more fit for human existence than exists at present. A grave responsibility rests upon the Government of this country in both these respects, and inperial legislation must no longer be delayed to render it impossible for local sanitary authorities to neglect a duty so manifestly necessary to put an end to this pernicious system, which is sapping the life blood and destroying the vital powers of so many town dwellers. The gratitude of every thinking man is due to THE LANCET for exposing the destructive agencies at work amongst the toiling classes, who are incapable themselves of doing anything to lessen the disabilities of life.

It may pertinently be asked, What is the remedy to hinder further degradation of racial power, and rescue the town dwellers from the agencies so powerfully operating upon their physical competency? I fully recognise the cogency of such a question, but I must at once admit my inability to suggest a satisfactory answer. It may to some extent be found in arlopting legislative measures. No doubt sanitary reform is doing an excellent work. Insanitary surroundings, overcrowding, uncleanliness, impurity, and intemperance must all be done away with or lessened. Educate the children in the pure air of the country, make the parents aware of the great constitutional value of sobriety and morality, give them all pure air and plenty of it, and away fly the pale faces, cachexia, lowered vitality, stunted development, muscular attenuation, and the imperfect elimination of functional products.

I observe the Anthropometric Committee has instituted an inquiry as to the influence of occupation on the physical development and conformation of the body, and Manchester has been selected as the best place to carry out the research, chietly because its racial elements are pretty uniform, and it possesses a great diversity of industries. Such an inquiry will necessarily embrace a variety of facts as to health, fit ness of occupation, relative injury sustained as to arrest of physical development and other constitutional characteristies of town dwellers. If well oroanised and well carried out, such an inquiry will define and determine many points hitherto shrouded in obseurity, and it is obvious that an extensive investigation of this kind will lead to satisfactory results. The purely physical side of human nature demands our attention. The instinctive rush of the poorer people into the towns in quest of means to live has greatly helped to complicate the problen of relief. Hardships of various kinds tend to accentuate their wretchedness, and they seek solace tuo often in the unhealthy pursuit of unrighteous habits. The problem of physical degeneracy has to be reckoned with if the English race in our large towns is to retain a fair standard of physical integrity.

Southport.

\section{ON SUTURE OF THE URETHRA IN CASES OF PERINEAL SECTION.}

By A. MARMADUKE SHEILD, M.B.CANTAB., F.R.C.S., ASSISTANT SURGEON TO CHARIYG-CROSS HOSPITAL.

I vENTURE to call the attention of surgeons who may perform the operation of external urethrotomy to the practice of uniting the urethral wound by means of catgut sutures. In cases of perineal section as commonly practised, no attempt at closing the perineal or urethral incision is made. An indolent, deep, and suppurating wound results. At the bottom of this the introduced catheter is exposed, often for sereral weeks. Healing is protracted and unsound It may truly be said that by the aid of the fine catheters and bougies of the present day "impassable" strictures should hardly be found in the practice of a skilled surgeon. During the past two years I have met with three cases of stricture which resisted the passage of instruments, though of varied size and form, and used with all observation of patience, gentleness, and perseverance. In these patients, men of over forty years of age, who had long suffered from stricture the common conditions of perineal fibroid induration and great sensibility of the parts were observed. One of them had suffered for three months from sinus in the perineum. The operation was in all cases conducted after the fashion so well described and practised by Mr. Wheelhouse, the urethra being opened in front of the stricture. In the performance of urethral suture the following points were observed:1. The coverings of the urethra were divided by an incision of limited length, and the urethra was clearly defined and felt with the staff pressed against the face of the stricture. 2. The urethra was opened with a fine and very sharp knife, which did not push the fibrous tissue in front of it. 3. The stricture having been passed, incised, and a large gum instrument passed into the bladder, a series of catgut sutures were introduced through the margins of the cut urethra by means of a curved needle. They were placed close together, and, when tied, the catheter was quite concealed. The wound was now dusted with iodoform and the soft parts covering the urethra were united. This was effected by fine wire sutures deeply introduced. About one-third of the length of the incision was left open posteriorly to ensure drainage, and great care was taken that no pouch or pocket could be left in which discharge could accumulate.

The after-treatment to be carried out may be briefly indicated. The perineal wound must be kept clean, and supported with a pad of iodoform wool. The catheter should be retained in situ for a week, and the bladder washed out daily with warm boracic fluid. The silver sutures can be retained for fourteen days; they cause little irritation. The catheter should be worn for about a month, and frequently passed afterwards. In the three cases alluded to, union was speedy and complete. In only one of them did any urine leak through the wound. Twelve and eighteen months have elapsed in two of the cases since the performance of the operation, and the patients are able to micturate and pass large instruments with ease and comfort. I would venture to insist upon the importance of making the incisions with a very fine and sharp knife, and of checking all bleedin $\alpha$ by sponge pressure, and clearly defining the urethra in a good light before opening it. I have been unable to discover any published account of urethral or perineal suture in the works or writings of English surgeons.

I am quite aware that the experience of these three cases is insufficient to establish the value of this proceeding. But I think I am justified in calling the attention of surgeons to it, and trust that it may receive a trial in appropriate cases. Strictures which call for external division are comparatively rare. It is only by combined experience that the value of any operative moditication can be determined. stratford-place, $w$.

\section{ON VENTRAL FIXATION OF THE UTERUS FOR INTRACTABLE PROLAPSE.}

By JOHN PHILLIPS, B.A., M.B. Cantab., M.R.C.P., PHYSICIAN TO THE BRITISH LYING-IN HOSPITAL.

THE disease of which I propose to treat here is only too familiar to every practitioner, and its resistance to all varieties of treatment is equally well known. I wish to bring into more prominent notice an operation for its relief, which has been performed in Germany during the past two years more than once, and also in America, but of which, so far as I know, there is no published record in this country. Hitherto nearly all attempts to alleviate this most distressing condition have been directed towards the vagina by the performance of such operations as perineorrhaphy and elytrorrhaphy, the hope being that by constriction or complete closure of this passage the enlarged uterus might be kept in position. The futility of these 